\title{
Epidemiology of Traumatic Spinal Injury in North of Iran: A Cross-Sectional Study
}

\author{
Kaveh Haddadi ${ }^{*}$, Farzaneh Yosefzadeh ${ }^{2}$ \\ ${ }^{1}$ Assistant Professor, Department of Neurosurgery, Imam Khomeini hospital, Orthopedic Research Center, Mazandaran \\ University Of Medical Sciences, Sari, Mazandaran, Iran \\ ${ }^{2} \mathrm{MD}$, School of Medicine, Mazandaran University of Medical Sciences, Sari, Mazandaran, Iran \\ *Corresponding Author Address: Department of Neurosurgery, Imam Khomeini hospital, Orthopedic Research Center, \\ Mazandaran University Of Medical Sciences, Sari, Mazandaran, Iran. E mail:kh568hd@yahoo.com, Tel/Fax number: +98-11- \\ 33378789, Postal code: 48166-33131
}

Article Type: Research Article

Received: October 15, 2015, Last revised: February 9, 2016, Accepted: February 15, 2016

\section{Abstract}

Background \& Aim: Acute injuries of the spine and spinal cord are causing the greatest amount of disability. They produce high cost outcomes for patients and society psychologically and economically. Knowing the epidemiology of these injuries play an important role in planning for prevention and conservative treatment. But now, we have little information about this in our country. The aim of this study was to determine epidemiology of spinal injury in Sari Imam Khomeini hospital, main trauma center of Mazandaran, an Iranian province.

Methods \& Materials/Patients: The present cross-sectional study was conducted on all cases of traumatic spine injury, who were admitted in Sari Imam Khomeini hospital, main trauma center of Mazandaran, during 2012-2014. Checklist included demographic characteristics (age, gender, location), mechanism of injury of the spine, the level of injury detected by radiologic imaging and MRI and CT scans, the scoring systems for assessing the severity of injury that were American Spinal Injury Association (ASIA) scale and The Injury Severity Score.

Results: Among a total of 906 cases, $57.8 \%(n=523)$ were male and 42.2\% ( $(n=383)$ were female. Male/Female ratio was 1.37:1. The most common age group at which spinal injury occurred in males was 25-44 years-old, and in females was 45-64 years-old $(\mathrm{P}=0.044)$. The most frequent causative mechanism of trauma was traffic accidents (especially motorcycle-caused accidents). The most common injury in spine fracture was compression and burst types. Among 93 patients with abnormal findings on neurological examination, 45 of them had complete spinal cord injury (class A of ASIA) and 48 of them had incomplete spinal cord injury (class $\mathrm{B}, \mathrm{C}, \mathrm{D}$ of ASIA).

Conclusion: Motor vehicles accidents are the most common cause of spine and spinal cord injury in Mazandaran,a region of the North of Iran. The incidence of spinal cord injury is high if ISS is more than 12.

Keywords: Epidemiology; Spinal Injuries; Iran, Mazandaran

Please cite this paper as: Haddadi K, Yousefzadeh F. Epidemiology of Traumatic Spinal Injury in North of Iran: A Cross-sectional Study. Iran. J. Neurosurg. 2015;1(4): 11-14

\section{Introduction}

Spinal cord injury (SCI) is a highly destructive situation (1) which is related to severe disability and death after trauma (2). Incidence of SCI is 12.1-57.8 cases per million (1) .The cost to the patient, their family and the health care system can be enormous (3).

In the US, spinal cord injury is the most costly traumatic condition. Johnson et al. (4) in a prospective populationbased cohort study, reported for each patient, costs for home care, services, and secondary medical complications that reached almost $\$ 200,000$ during the first 2 years after injury. The average cost of the first admission is approximately $\$ 95,203$, with home modifications costing $\$ 8,203$, medical services and equipment costing $\$ 7,866$, and nurse and home care support costing $\$ 6,269$ per year (5). An understanding of the epidemiology of SCI is essential for planning cost-effective care and for developing preventive strategies (6). Significant changes in SCI prevalence were observed among geographic locales, so these data are principal for local and regional health care economics (5). Rahimi- Movaghar et al. (2009) performed a population-based study to determine the prevalence of spine injury (SI) and spinal cord injury (SCI) in Tehran, Iran (7). The prevalence of traumatic SCI in Tehran ranged from 1.2 to 11.4 per 10,000 people.

Traumatic spine fracture (TSF) can occur as an isolated lesion or associated with other injuries such as to the spinal cord, head, extremities, and other organs. Role of spine injury as a potential cause of disability and/or death is usually neglected. It commonly causes short-term disability (8), but may also result in long-term disability. Spine injury may be associated with permanent disability (9). Although the incidence of TSF increases in old population (5-8), it mostly involves young persons (10), which may increase the burden of this disease.

Although more than $80 \%$ of the world's population live in developing countries, little information is available 
regarding the epidemiology of SCI in these countries. The aim of the study was to determine regional epidemiology, demographics, mechanisms and severity of spine and spinal cord injury in a great area of north of Iran, Mazandaran.

\section{Methods and Materials/Patients}

Our cross-sectional study was performed on all patients with traumatic spine injury admitted to our hospital, the major trauma center in Mazandaran, an Iranian province, between January 2012 and November 2014.

The demographic characteristics, mechanism of trauma, level and type of spinal fracture detected by radiologic imaging and MRI and CT scans, were obtained. We used the American Spinal Injury Association (ASIA) scale and Injury Severity Score (ISS) for classifying the severity of injury.

According to ASIA scale, patients were classified as (A: complete; B, C, D: incomplete; E: normal) and on the basis of ISS, they were categorized as (severe: $>12$, moderate: 7-12, mild: $<7$ ). All data were analyzed by SPSS.

\section{Results}

Total of 906 patients with traumatic spine injury (SI) were identified ; $57.8 \%(n=523)$ of patients were male and $42.2 \%$ $(\mathrm{n}=383)$ were female. Male/female ratio was 1.37:1. (Table 1)

Table 1. Demographic Characteristics of Patients with Traumatic Spinal Injury

\begin{tabular}{|c|c|c|}
\hline Sex & Number & Mean Age (Year \pm SD) \\
\hline Male & 523 & $32.3 \pm 22.33$ \\
\hline Female & 383 & $38.6 \pm 26.11$ \\
\hline Male/Female Ratio & $1.37 / 1$ & - \\
\hline
\end{tabular}

The peak frequency of SI in males occurred in 25-44 yearold age group, and in females took place in 45-65 year-old age group. Men were significantly younger than women $(\mathrm{p}=0.044)$.

Traffic accidents were the most common cause of spine injury $(71.6 \%)$. The remaining ones were fall $(26.5 \%)$ and other mechanisms $(1.8 \%)$.

Traffic accidents tended to occur in younger age group (90.9\% in $15-24$ year-olds), whereas falls tended to happen in older patients $(38.5 \%$ in $>64$ years-old $)(p=0.004)$ (Figure 1$)$. Thoracolumbar fractures were more common in patients with motor vehicle accidents $(74.1 \%)$, while thoracic fractures were more common in fall patients (40\%). Table 2 shows the incidence of spinal fractures from traumatic causes based on spinal area.

93 out of 906 patients with spinal trauma had abnormal finding on neurological examination $(10.2 \%) .45(4.9 \%)$ patients were classified as having ASIA A injuries. $48(5.29 \%)$ patients had ASIA B,C,D (Table 3). 23 patients with complete spinal cord injury had tetraplegia, and 22 patients $(48.8 \%)$ had paraplegia. 23 patients with complete spinal cord injuries $(51 \%)$ had fracture or dislocation of cervical spine. Tetraplegia occurred in $12(25 \%)$ patients with incomplete SCI, and paraplegia occurred in $12(25 \%)$ patients, and $24(50 \%)$ of patients with incomplete SCI had no plegia. ISS $>12$ was seen in $43 \%$ of patients with thoracolumbar injuries, and $35 \%$ of patients with cervical injuries and $40 \%$ of cases of thoracic injuries. $36.2 \%$ of spinal fractures were caused by traffic accident injury, while $27.9 \%$ of them resulted from fall.
Table 2. Incidence of Spinal Fractures related to Spinal Area

\begin{tabular}{|c|c|}
\hline Level of Injury & Number of Cases \\
\hline Cervical & 189 \\
\hline Thoracic & 77 \\
\hline Thoracolumbar & 492 \\
\hline Lumbosacral & 148 \\
\hline
\end{tabular}

Table 3. Incidence of Severity of Trauma and Abnormal Finding on Neurological Examination according to Trauma Mechanism

\begin{tabular}{|c|c|c|c|c|c|c|}
\hline Total & Chance & Burst & Fracture- & Compression & \multicolumn{2}{|c|}{ Classification } \\
\hline $\begin{array}{c}360 \\
(39.7 \%)\end{array}$ & $\begin{array}{c}15 \\
(1.6 \%)\end{array}$ & $\begin{array}{c}102 \\
(11.2 \%)\end{array}$ & $\begin{array}{c}7 \\
(0.7 \%)\end{array}$ & $\begin{array}{c}236 \\
(26 \%)\end{array}$ & Mild & \multirow{3}{*}{ ISS } \\
\hline $\begin{array}{c}180 \\
(19.9 \%)\end{array}$ & $\begin{array}{c}10 \\
(1 \%)\end{array}$ & $\begin{array}{c}51 \\
(5 \%)\end{array}$ & $\begin{array}{c}11 \\
(1.2 \%)\end{array}$ & $\begin{array}{c}108 \\
(11.9 \%)\end{array}$ & Moderate & \\
\hline $\begin{array}{c}366 \\
(40.4 \%)\end{array}$ & $\begin{array}{c}22 \\
(2 \%)\end{array}$ & $\begin{array}{c}198 \\
(21 \%)\end{array}$ & $\begin{array}{c}28 \\
(3 \%)\end{array}$ & $\begin{array}{c}118 \\
(13 \%)\end{array}$ & Severe & \\
\hline $\begin{array}{c}45 \\
(9.9 \%)\end{array}$ & $\begin{array}{c}5 \\
(0.5 \%)\end{array}$ & $\begin{array}{c}8 \\
(0.8 \%)\end{array}$ & $\begin{array}{c}30 \\
(3 \%)\end{array}$ & $\begin{array}{c}2 \\
(0.2 \%)\end{array}$ & A & \multirow{3}{*}{ ASIA } \\
\hline $\begin{array}{c}48 \\
(10.6 \%)\end{array}$ & $\begin{array}{c}4 \\
(0.4 \%)\end{array}$ & $\begin{array}{c}24 \\
(13.3 \%)\end{array}$ & $\begin{array}{c}8 \\
(0.8 \%)\end{array}$ & $\begin{array}{c}12 \\
(1 \%)\end{array}$ & $\mathrm{B} \& C \& D$ & \\
\hline $\begin{array}{c}813 \\
(89.73 \%)\end{array}$ & $\begin{array}{c}1 \\
(0.1 \%)\end{array}$ & $\begin{array}{c}228 \\
(25.1 \%)\end{array}$ & $\begin{array}{c}0 \\
(0 \%)\end{array}$ & $\begin{array}{c}584 \\
(64.4 \%)\end{array}$ & E & \\
\hline
\end{tabular}

\section{Discussion}

At present, reporting on prevalence of spinal injury in Iran is conducted very little (4-7). This is a prospective cross sectional study on the SCI patients admitted in the major trauma center in Mazandaran, an Iranian province from 2012 to 2014. According to our study, injuries in males were more than those in females. In previous studies' reports, our findings have been confirmed (11-19). Ning et al. (2010) did systematic review in Asia; they found that men were subject to higher risk of TSCI than women (20). This difference may be caused by social expectations that men should support their family and men tend to do dangerous works to get more money. Peak of injury in males occur in 25-44 yearolds (Figure 1), and traffic accident was the most common cause of SCI in 25-44 year-olds. This finding is similar to Yousefzadeh et al. (2008) and Taghipour et al. (2005) and Fakharian et al results.(2003) $(9,11,21)$. In all countries, the highest incidences were reported in persons aged between 20 and 50 years (22). The average age in North America (23) was between 32 and 55.4 years, and in Europe (14-16,24, 25 ) was between 37 and 47.9 years. Asian studies reported an average age between 26.8 to 56.6 years (20). These similar estimations in the world indicate that most cases of traumatic spine injury (TSI) are observed in adults because they are the most active members of society, and despite regional and demographic differences, these studies confirm worldwide tendency.

Traffic accidents are the most common cause of TSI in Europe (14,26-28), North America (29-32) and sub-Saharan Africa (33). In western Norway (34), falls were the most common cause. Ning et al. (2010) reported MVCs and falls were the main causes in Asia and the latter has been increasing (20). In underdeveloped areas in Asia, motor vehicle usage is not as common as in North America and Europe (20). In China (35, 36) there was a large group of old patients with degenerative cervical spine changes who were more exposed to a minor damage (e.g. a low fall), so the number of low falls-induced TSI gradually increased. Common cause in Bangladesh, (37, 38 ) is falls, while carrying heavy loads on neck or back. 


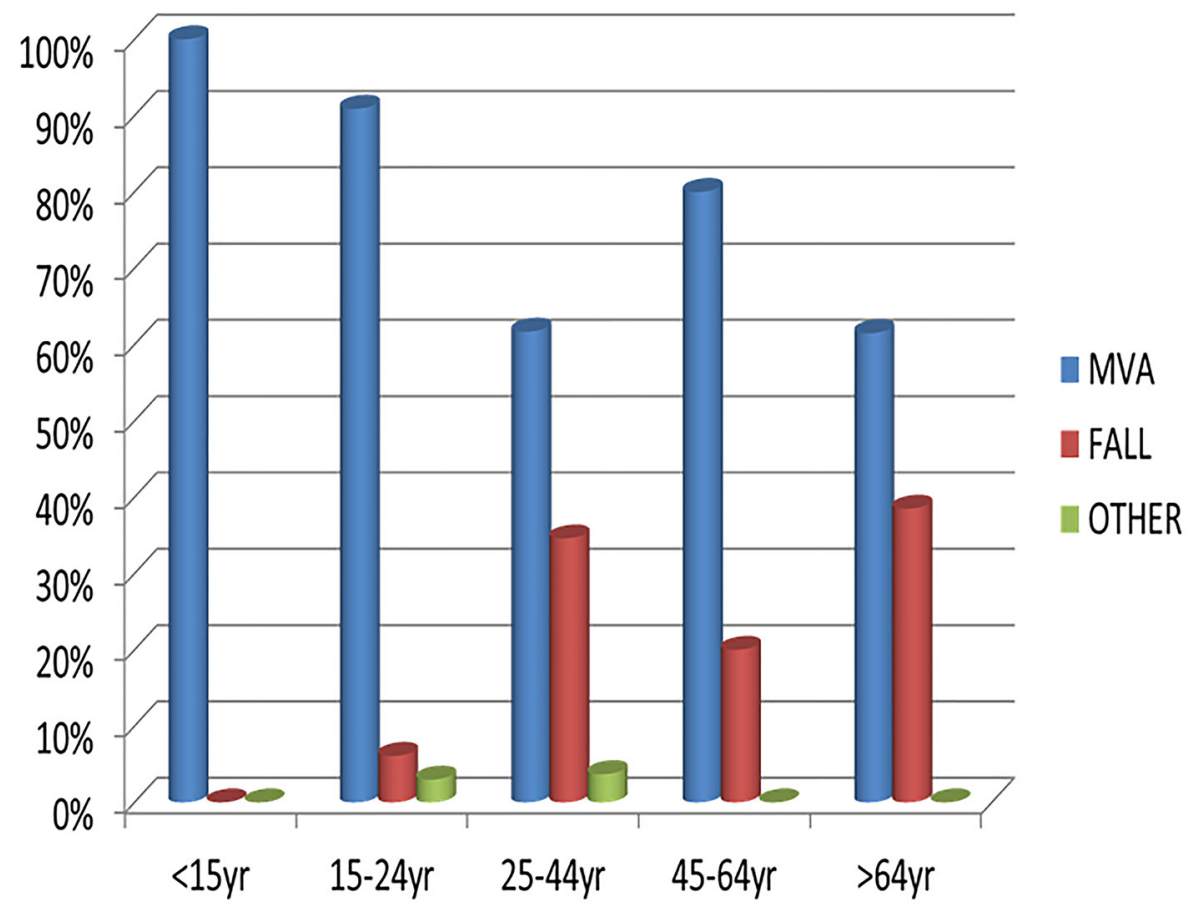

Figure 1. Cause of Traumatic Spinal Injury Categorized by Age Group

Firearm wounds is a specific problem in Afghanistan (39), Jordan (40) and southeastern Turkey (41).

Variation of life style in different countries and different regions of a country influence mechanism of trauma.

Yousefzadeh et al. (2008) showed thoracolumbar spine was common area for fracture (42). In our study, thoracolumbar spine was common involved area for traffic accidents, and thoracic spine was common site for falling. But Heidari et al. (2010) reported that cervical spine fractures were significantly frequent in road traffic accidents and lumbar fractures were common in accidental falls $(p<0.001)(12)$.

We obtained ISS $>12$ in falling were more than that in traffic accident. This is contrary to finding of Heidari (12). This disagreement may be due to difference in life style of people in different areas. Abnormal neurological examination occurred in $11.27 \%$ of patients. This is similar to Yousefzadeh et al. (2008) and Fakharian et al. findings (2003) $(9,42)$.

In short, as many studies, we found that traffic accidents and falls from height are the most common cause of spinal injury. So, education and prevention with strict traffics laws and optimization of transport and improving people's living and working conditions can be effective in reducing spinal damages. Our study was the first investigation that was designed to analyze spinal injury in Mazandaran. In a localized Sari environment, the present study showed a considerable amount of spinal cord injury which was mainly due to simultaneous associated injuries and associated trauma in subjects with spinal injury. The results of our study will be used to recommend policy makers, prioritizing preventive measures, support the evaluation of interventions, and give guidance on the degree of injury and disability following specific types of TSF. Considering the high proportion of associated injuries in spinal injury, it is suggested that policy makers must provide preventive strategies to reduce the number and severity of spinal injury. Development of a nationwide SCI registry or observation system is essential to an understanding of the epidemiology, and the prevention of this costly health problem.

\section{Conclusion}

Motor vehicles accidents are the most common cause of spine and spinal cord injury in Mazandaran, a region in the north of Iran. Thoracolumbar fracture was more common in patients with motor vehicle accidents. The incidence of spinal cord injury is high if ISS $>12$. Education and prevention with strict traffics laws can be effective on reducing damage to spine.

\section{Recommendation}

For rehabilitation period of treatment, we recommended designing a multicentric study in all cities of Mazandaran with 5 year period followed by long term follow-up of all patients discharging from hospital. Calculating cost of the first admission and rehabilitation period of patients with spinal injury is mandatory in future.

\section{Funding}

None.

\section{Conflicts of Interest}

The authors have no conflicts of interest.

\section{References}

1. Van den Berg, M., et al., Incidence of spinal cord injury worldwide: a systematic review. Neuroepidemiology, 2010. 34(3): p. 184-192.

2 . Flemming, K., R. Brown Jr, and H. Winn, Youmans Neurological Surgery. Youmans Neurological Surgery, 2004.

3. Dryden, D., et al., Direct health care costs following traumatic spinal cord injury. Annals of Epidemiology, 2004. 14(8): p. 611-612.

4. Wyndaele, M. and J.-J. Wyndaele.Incidence, prevalence and epidemiology of spinal cord injury: what learns a worldwide literature survey?Spinal cord, 2006. 44(9): p. 523-529.

5.Pickelsimer, E., E.J. Shiroma, and D.A. Wilson. Statewide investigation of medically attended adverse health conditions of persons with spinal cord injury. The journal of spinal cord medicine, 2010. 33(3): p. 221.

6. Lee, B., et al. The global map for traumatic spinal cord injury epidemiology: update 2011, global incidence rate. Spinal cord, 2013. 52(2): p. 110-116. 
7. Rahimi-Movaghar, V., et al. Prevalence of spinal cord injury in Tehran, Iran. The journal of spinal cord medicine, 2009. 32(4): p. 428.

8. Ackery, A., C. Tator, and A. Krassioukov.A global perspective on spinal cord injury epidemiology. Journal of neurotrauma, 2004. 21(10): p. 1355 1370.

9. Fakharian, E., et al. Incidence of mild head injury, management, and expenses in Kashan, 2003-2004. Feyz Journal of Kashan University of Medical Sciences, 2007. 11(3)

10. Rasouli, M.R., M. Nouri, and V. Rahimi-Movaghar. Spinal cord injuries from road traffic crashes in southeastern Iran. Chinese journal of traumatology 2007. 10(6): p. 323- 326.

11. Chabok, S.Y., et al. Epidemiology of traumatic spinal injury: a descriptive study.Acta Medica Iranica, 2010. 48(5): p. 308-311.

12. Pedram, H., et al. Spinal fractures resulting from traumatic injuries. Chinese Journal of Traumatology (English Edition), 2010. 13(1): 3-9.

13. Quinones, P.M., et al. Traumatic spinal cord injury in Qatar: an epidemiological study. Middle East J Emergency Med, 2002. 2(1): p. 35-40. 14. Knisdttir, S., et al. Epidemiology of traumatic spinal cord injuries in Iceland from 1975 to 2009.Spinal cord, 2011. 50(2): p. 123-126.

15. Amin, A., et al. Spinal injuries admitted to a specialist centre over a 5-year period: a study to evaluate delayed admission. Spinal cord, 2005. 43(7): p. 434-437.

16. O'Connor, R. and P. Murray.Review of spinal cord injuries in Ireland Spinal Cord, 2005. 44(7): p. 445-448.

17. O'Connor, P.J. Forecasting of spinal cord injury annual case numbers in Australia. Archives of physical medicine and rehabilitation, 2005. 86(1): p. 48-51.

18. Obalum, D., et al. Profile of spinal injuries in Lagos, Nigeria. Spinal Cord, 2008. 47(2): p.134-137.

19. Maharaj, J.C. Epidemiology of spinal cord paralysis in Fiji. 1985-1994 Spinal Cord, 1996. 34(9): p. 549-559.

20. Ning, G.Z., et al.Epidemiology of traumatic spinal cord injury in Asia: a systematic review. The journal of spinal cord medicine, 2012. 35(4): p. 229239.

21. Taghipour, M. and Sherafat Kazemzadeh,E.column and spinal cordinjuries in shiraz nemazi hospital, an epidemiological study.armaghan danesh, 2005. 11(4):52- 62 .

22. Nobunaga, A.I., B.K. Go, and R.B. Karunas.Recent demographic and injury trends in people served by the Model Spinal Cord Injury Care Systems. Archives of physicalmedicine and rehabilitation,1999. 80(11): 1372- 1382.

23. Calancie, B., M.R. Molano, and J.G. Broton. Epidemiology and demography of acute spinal cord injury in a large urban setting. The journal of spinal cord medicine, 2004.28(2):92-96

24. Dahlberg, A., et al.Prevalence of spinal cord injury in Helsinki. Spinal Cord, 2004. 43(1):47-50.

25. Divanoglou, A. and R. Levi.Incidence of traumatic spinal cord injury in Thessaloniki, Greece and Stockholm, Sweden: a prospective populationbased study. Spinal Cord, 2009. 47(11): p. 796-801.

26. Martins, F., et al.Spinal cord injuries--epidemiology in Portugal's central region. Spinal cord, 1998.36(8): p. 574-578.

27. Silberstein, B. and S. Rabinovich.Epidemiology of spinal cord injuries in Novosibirsk, Russia. Spinal Cord,1995. 33(6): p. 322-325.

28. Van Asbeck, F., M. Post, and R. Pangalila.An epidemiological description of spinal cord injuries in The Netherlands in 1994. Spinal cord, 2000. 38(7): p. 420-424.

29. Dryden, D.M., et al.The epidemiology of traumatic spinal cord injury in Alberta, Canada. The Canadian Journal of Neurological Sciences, 2003. 30(2): p. 113-121.

30. Pickett, G.E., et al.Epidemiology of traumatic spinal cord injury in Canada. Spine, 2006. 31(7): p. 799-805.

31. Surkin, J., et al.Spinal cord injury in Mississippi: findings and evaluation, 1992-1994. Spine, 2000. 25(6): p. 716-721.

32. Pirouzmand, F. Epidemiological trends of spine and spinal cord injuries in the largest Canadian adult trauma center from 1986 to 2006: clinical article Journal of neurosurgery: Spine, 2010. 12(2): 131-140.

33. Draulans, N., et al.Etiology of spinal cord injuries in SubSaharan Africa. Spinal cord, 2011. 49(12): 1148-1154.

34. Hagen, E.M., et al.A 50-year follow-up of the incidence of traumatic spinal cord injuries in Western Norway.Spinal Cord, 2009. 48(4): p. 313-318. 35. Ning, G., et al.Epidemiology of traumatic spinal cord injury in Tianjin, China. Spinal Cord, 2010. 49(3): 386-390.

36. Feng, H.Y., et al. Epidemiological profile of 239 traumatic spinal cord injury cases over a period of 12 years in Tianjin, China.The journal of spinal cord medicine, 2011. 34(4):388- 394.

37. Hoque, M.F., C. Grangeon, and K. Reed.Spinal cord lesions in Bangladesh: an epidemiological study 1994-1995. Spinal cord, 1999.37(12): 858-861.

38. Islam, M., M. Hafez, and M. Akter.Characterization of spinal cord lesion in patients attending a specialized rehabilitation center in Bangladesh.Spinal cord, 2011. 49(7):783-786.

39. Deconinck, H., The health condition of spinal cord injuries in two Afghan towns. Spinal Cord, 2003. 41(5): 303-309.

40. Otom, A., et al., Traumatic spinal cord injuries in Jordan- -an epidemiological study. Spinal Cord, 1997. 35(4): p. 253- 255.

41. Karamehmetoğlu, S., et al.Traumatic spinal cord injuries in southeast Turkey: anepidemiological study. Spinal Cord, 1997. 35(8): 531-533

42. Yousefzadeh, S., et al.Epidemiology of head injury in patients whowere referred to poorsina hospital. Journal of Guilin University of Medical Sciences, 2008. 